\title{
Comparison of Surface Irrigation Simulation Models: Full Hydrodynamic, Zero Inertia, Kinematic Wave
}

\author{
Mohammad Valipour ${ }^{1}$ \\ ${ }^{1}$ Irrigation and Drainage Engineering College, College of Abureihan, University of Tehran, Pakdasht, Tehran, Iran \\ Correspondence: Mohammad Valipour, Irrigation and Drainage Engineering College, College of Abureihan, \\ University of Tehran, Pakdasht, Tehran, Iran. Tel: 98-212-630-0812. Email: vali-pour@hotmail.com
}

Received: August 27, 2012 Accepted: September 19, 2012 Online Published: November 15, 2012

doi:10.5539/jas.v4n12p68 URL: http://dx.doi.org/10.5539/jas.v4n12p68

\begin{abstract}
Some phenomena such as surface irrigation are so complex that it is very difficult to implement them in nature. For this purpose, simulation models are used. In this study, ability of full hydrodynamic, zero inertia, and kinematic wave models has been investigated in surface irrigation simulation. Using SIRMOD software, their performance has been compared. The results showed that full hydrodynamic and zero inertia models were very powerful in simulation process. For increasing of filed slope until amount of 0.01 full hydrodynamic and zero inertia models had not any difference but for more increasing of $S_{0}$ due to the increasing of velocity, accuracy of zero inertia model dropped. In full hydrodynamic and zero inertia models for increase in Manning's roughness coefficient amount of error was increased until $n=0.15$. After this amount, error remained constant thus $n=0.15$ determined as critical discharge. Accuracy of kinematic wave model reduced in clay and heavy clay soils, high discharges, high Manning's roughness coefficient, and basin irrigation. However, in many situations all three models had the same answers and were capable tools to simulating of surface irrigation processes.
\end{abstract}

Keywords: basin irrigation, border irrigation, full hydrodynamic, kinematic wave, SIRMOD, zero inertia

\section{Introduction}

Surface Irrigation Simulation Models are widely applied, which some of them will be described in the following.

Moravejalahkami, Mostafazadeh-Fard, Heidarpour and Abbasi (2009) using a zero-inertia model with a multilevel calibration approach predicted furrow infiltration and roughness for different furrow inflow hydrographs. The infiltration Equation developed by the method simulated the field data more accurately than the two-point method with the zero-inertia model. The multilevel calibration method predicted the total volume of runoff, total volume of infiltration and furrow outflow hydrograph shapes with lower relative errors compared to the two-point method for the different furrow inflow hydrograph shapes. Khanna and Malano (2006) reviewed modeling of basin irrigation systems. Their results showed that availability of accurate values of surface irrigation parameters such as Manning's roughness coefficient and infiltration coefficients for the empirical Equations was often a problem in the application of these models. Holzapfel et al. (2004) studied Infiltration parameters for furrow irrigation. They showed that using the kinematic wave model and the Kostiakov constants obtained with the advance model; simulate better the advance phase of the waterfront in the furrow. Maheshwari, McMahon and Turner (1990) investigated sensitive analysis of parameters of border irrigation models successfully. Raghuwanshi and Wallender (1998) to incorporate an economic optimization submodel modified a seasonal furrow irrigation model consisting of irrigation scheduling and kinematic wave based hydraulic submodels. Bautista (1991) validated the kinematic simulation of surge border irrigation. The results of the computer simulations agreed with measured results. Ito, Wallender and Raghuwanshi (2005) using kinematic wave model determined optimal sample size for furrow irrigation design. The results showed that 3 samples per 9 ha block can be used for representing spatial variability in managing the furrow irrigation for the conditions studied. Maheshwari (1992) using kinematic wave model studied effects of recession criteria on prediction of recession times in border irrigation models. The prediction of the models for a given recession criterion varied considerably with the events and indicated that other factors affecting flows in border irrigation should also be taken into account while selecting a recession criterion. Walker and Humpherys (1984) developed and verified a kinematic wave model of furrow irrigation under both continuous and surged flow management. Ram and Singh (1982) evaluated kinematic wave, empirical, and volume balance models for border irrigation recession. Perez, Camacho, Roldan, Alcaide and Reca (1995) using 
kinematic wave model designed a control system of furrow irrigation in real time successfully. Hume (1993) determined infiltration characteristics by volume balance model for border check irrigation. The volume balance technique assumes that water infiltrates only into the soil that was covered by the advancing irrigation water. This assumption held for soils in the "fully irrigated" state where soil moisture levels were high enough to prevent extensive cracks, it was invalid in dry soils where extensive shrinkage cracks develop. Under these conditions, the form of the infiltration characteristic was wrongly predicted leading to an overestimate for infiltration. Raghuwanshi and Wallender (1998) using kinematic wave model determined optimal furrow irrigation scheduling under heterogeneous conditions. The Natural Resource Conservation Service recommended irrigation adequacy for homogeneous soil condition was $87.5 \%$. For any given irrigation interval, optimal irrigation required less $(48-63 \%)$ water than full irrigation. This also reduced both the deep percolation and runoff losses and caused a $31-43 \%$ increase in the application efficiency. Furthermore, loss in revenue due to yield reduction was less than the savings in irrigation cost, which resulted in higher (32-54\%) net return to water under the optimal irrigation compared with full irrigation. These results indicated that the optimal irrigation strategy had potential not only for water conservation, but also for reducing non-point source pollution. Parsa and Sepaskhah (1991) using zero inertia model modified Fok-Bishop solution for determination of water advance in border irrigation. For borders longer than 100 meter in which the slope was steeper than $0.005 \mathrm{~m} / \mathrm{m}$, the Fok-Bishop Equation could predict the water advance curve on borders. However, for shorter borders and/or slopes smaller than $0.005 \mathrm{~m} / \mathrm{m}$ the proposed modification to the Fok-Bishop Equation could be used to predict the water advance more accurately. Reddy and Clyma (1982) using zero inertia model analyzed basin irrigation performance with variable inflow rate. Significant reductions in system performance occurred when the average flow rate was equal to $50 \%$ of the design. Basin irrigation systems should be designed for the average of the variable flow rate available at the field outlet. Yitayew (1987) using zero inertia model studied interrelationship of performance parameters for irrigation borders. The developed relationships were useful in designing border irrigation systems mainly to check the design time of cutoff, inflow rate, etc. for an expected level of uniformity and application efficiencies. Alazba (1998) used zero inertia model to studied necessity for modification of management parameters when using low quality water. The results showed that the management parameters, application rate and time, needed to be modified when treated wastewater was alternatively used in lieu of normal water for which the system was supposedly designed to obtain maximum efficiency. Clemmens (1981) using zero inertia model evaluated infiltration measurements for border irrigation. The zero inertia model was also used to examine the effect of different infiltration functions for specific examples (resulting from different irrigations or different estimation methods) on the application of water by the surface irrigation. He showed that when good information was obtained on infiltration, the zero inertia border irrigation model could be a useful tool in helping to improve irrigation water use.

According to the pervious researches applications of surface irrigation simulation models studied in many fields. However, comparing of these models for investigate amount of their errors and limitations has not been done. In this paper by using SIRMOD software performance of surface irrigation simulation models was compared.

\section{Materials and Methods}

The full hydrodynamic model is based on governing Equations in the form of the Saint-Venant Equations:

$$
\begin{gathered}
\frac{\partial y}{\partial t}+\frac{\partial q}{\partial x}+\frac{\partial z}{\partial t}=0 \\
\frac{\partial q}{\partial t}+\frac{2 q \partial q}{y \partial x}+g y \frac{\partial y}{\partial x}=g y\left(S_{0}-S_{f}\right)
\end{gathered}
$$

Where, $y(\mathrm{~m})$ is depth of flow, $q\left(\mathrm{~m}^{3} / \mathrm{s} . \mathrm{m}\right)$ is discharge in width unit, $z\left(\mathrm{~m}^{3} / \mathrm{m}\right)$ is volume of infiltrated in length unit, $g\left(\mathrm{~m} / \mathrm{s}^{2}\right)$ is gravity accelerate, $S_{0}(\mathrm{~m} / \mathrm{m})$ is field slop, $S_{f}(\mathrm{~m} / \mathrm{m})$ is energy gradient.

In surface irrigation because velocity is low, inertia is low too thus neglect inertia terms and by simplifying of Equation (2), zero inertia model is founded:

$$
\frac{\partial y}{\partial x}=S_{0}-S_{f}
$$

In addition, in kinematic wave model (uniform flow model) due to slight changes in depth consider the depth as normal depth (assuming flow uniformity):

$$
S_{0}=S_{f}
$$


Using Surface Irrigation Model (SIRMOD) ability of full hydrodynamic, zero inertia, and kinematic wave models compared. Table 1 shows input data for evaluating of models in border irrigation and basin irrigation.

Table 1. Input data for SIRMOD software

\begin{tabular}{ccccccc}
\hline $\mathrm{Q}_{\text {in }}(\mathrm{l} / \mathrm{s})$ & $\mathrm{T}_{\mathrm{c}}(\mathrm{min})$ & $\mathrm{L}(\mathrm{m})$ & $\mathrm{n}\left(\mathrm{s} / \mathrm{m}^{1 / 3}\right)$ & $\mathrm{S}_{0}(\mathrm{~m} / \mathrm{m})$ & $\mathrm{IF}$ & Soil texture \\
\hline 1.2 & 300 & 300 & 0.10 & 0.00196 & 0.45 & Silty loam \\
\hline
\end{tabular}

\section{Results and Discussion}

Table 2 shows obtained results from running of SIRMOD software for input data in border and basin irrigations.

Table 2. Output data from SIRMOD software

\begin{tabular}{|c|c|c|c|c|c|c|c|c|c|}
\hline Model & $\begin{array}{l}\text { Advance } \\
\text { time } \\
(\min )\end{array}$ & $\begin{array}{c}\text { Application } \\
\text { efficiency } \\
(\%)\end{array}$ & $\begin{array}{l}\text { Distribution } \\
\text { uniformity } \\
(\%)\end{array}$ & $\begin{array}{c}\text { Deep } \\
\text { percolation } \\
(\%)\end{array}$ & $\begin{array}{c}\text { Tailwater } \\
(\%)\end{array}$ & $\begin{array}{l}\text { Inflow } \\
\left(\mathrm{m}^{3}\right)\end{array}$ & $\begin{array}{l}\text { Outflow } \\
\qquad\left(\mathrm{m}^{3}\right)\end{array}$ & $\begin{array}{l}\text { Infiltration } \\
\left(\mathrm{m}^{3}\right)\end{array}$ & $\begin{array}{c}\text { Error } \\
(\%)\end{array}$ \\
\hline $\begin{array}{l}\text { Full } \\
\text { Hydrodynamic }\end{array}$ & 214.3 & 69.32 & 90.41 & 13.72 & 16.97 & 21.5 & 3.6 & 17.9 & 0.32 \\
\hline Zero Inertia & 214.3 & 69.31 & 90.40 & 13.72 & 16.96 & 21.5 & 3.6 & 17.9 & 0.32 \\
\hline $\begin{array}{l}\text { Kinematic } \\
\text { Wave }\end{array}$ & 215.1 & 69.40 & 99.93 & 12.25 & 18.35 & 21.5 & 3.9 & 17.6 & 0.32 \\
\hline
\end{tabular}

According to the Table 2 although there is little difference between amount of efficiencies in all three models, but amount of models error is equal and negligible. Amount of error achieves by comparing inflow, outflow, and infiltration volumes. Then for comparing sensitive of models to different conditions, by changing each of six input parameters in Table 1, amount of obtained error from simulation models investigated. Table 3 shows changes of models error for different discharges.

Table 3. Changes of models error for different discharges

\begin{tabular}{lllllllllll}
\hline \multirow{2}{*}{ Model } & \multicolumn{1}{c}{$\mathrm{Q}_{\text {in }}(\mathrm{l} / \mathrm{s})$} \\
\cline { 2 - 10 } & 0.5 & 1.0 & 1.2 & 1.5 & 2.0 & 5.0 & 7.0 & 10.0 & 12.0 & 15.0 \\
\hline Full Hydrodynamic & 0.06 & 0.23 & 0.32 & 0.38 & 0.43 & 0.49 & 0.46 & 0.45 & 0.44 & 0.42 \\
Zero Inertia & 0.06 & 0.23 & 0.32 & 0.38 & 0.43 & 0.49 & 0.46 & 0.45 & 0.44 & 0.42 \\
Kinematic Wave & 0.35 & 0.23 & 0.32 & 0.38 & 0.43 & 0.72 & 2.13 & 9.89 & 11.30 & 10.63 \\
\hline
\end{tabular}

In Table 3 for different discharge amount of error in full hydrodynamic and zero inertia models is equal. In these two models for increase in discharge amount of error was increased until $\mathrm{Q}_{\text {in }}=5.0 \mathrm{l} / \mathrm{s}$. After this discharge error reduced thus $\mathrm{Q}_{\text {in }}=5.0 \mathrm{l} / \mathrm{s}$ determined as critical discharge. In full hydrodynamic and zero inertia models whatever amount of discharge is less, accuracy of simulation models is more. In kinematic wave model the best simulation occurred in $\mathrm{Q}_{\text {in }}=1.0 \mathrm{l} / \mathrm{s}$ and for discharges less and more than this amount, error increased. $\mathrm{Q}_{\text {in }}=12.0 \mathrm{l} / \mathrm{s}$ determined as critical discharge in kinematic wave model. To simulation of border and basin irrigations with discharges of more than 7.0 liters per second should be careful in using this model.

Table 4 shows changes of models error for different cutoff times.

Table 4. Changes of models error for different cutoff times

\begin{tabular}{lllllllllll}
\hline \multirow{2}{*}{ Model } & \multicolumn{10}{c}{$\mathrm{T}_{\mathrm{c}}(\mathrm{min})$} \\
\cline { 2 - 9 } & 180 & 240 & 300 & 360 & 480 & 600 & 720 & 900 & 1200 & 1320 \\
\hline Full Hydrodynamic & 0.27 & 0.31 & 0.32 & 0.32 & 0.31 & 0.31 & 0.31 & 0.31 & 0.31 & 0.31 \\
Zero Inertia & 0.27 & 0.31 & 0.32 & 0.32 & 0.31 & 0.31 & 0.31 & 0.31 & 0.31 & 0.31 \\
Kinematic Wave & 0.27 & 0.31 & 0.32 & 0.32 & 0.31 & 0.31 & 0.31 & 0.31 & 0.31 & 0.31 \\
\hline
\end{tabular}


In Table 4 for different cutoff times amount of error in all three models is equal. It means that accuracy of models is not sensitive to changes of cutoff times in difference with together. For increase in cutoff time until 5-6 hr, amount of error increased and then remained constant. Thus $T_{c}=5-6 \mathrm{hr}$ selected as critical cutoff time.

Table 5 shows changes of models error for different length of border or basin.

Table 5. Changes of models error for different lengths of border or basin

\begin{tabular}{ccccccccccc}
\hline \multirow{2}{*}{ Model } & \multicolumn{10}{c}{$\mathrm{L}(\mathrm{m})$} \\
\cline { 2 - 11 } & 30 & 33 & 38 & 43 & 50 & 60 & 75 & 100 & 150 & 300 \\
\hline Full Hydrodynamic & 0.11 & 0.12 & 0.14 & 0.15 & 0.17 & 0.20 & 0.23 & 0.27 & 0.33 & 0.32 \\
Zero Inertia & 0.11 & 0.12 & 0.14 & 0.15 & 0.17 & 0.20 & 0.23 & 0.27 & 0.33 & 0.32 \\
Kinematic Wave & 0.11 & 0.12 & 0.15 & 0.15 & 0.17 & 0.20 & 0.23 & 0.27 & 0.33 & 0.32 \\
\hline
\end{tabular}

In Table 5 situations are govern such as Table 4. Accuracy of models is not sensitive to changes of length of border or basin in difference with together too. For half of length of border or basin critical length was occurred. For miniaturize length more than this amount accuracy of simulation was increased.

Table 6 shows changes of models error for different Manning's roughness coefficient.

Table 6. Changes of models error for different Manning's roughness coefficients

\begin{tabular}{lllllllllll}
\hline \multirow{2}{*}{ Model } & \multicolumn{10}{c}{$\mathrm{n}\left(\mathrm{s} / \mathrm{m}^{1 / 3}\right)$} \\
\cline { 2 - 11 } & 0.02 & 0.03 & 0.05 & 0.10 & 0.12 & 0.15 & 0.17 & 0.20 & 0.22 & 0.25 \\
\hline Full Hydrodynamic & 0.27 & 0.28 & 0.29 & 0.32 & 0.32 & 0.33 & 0.33 & 0.33 & 0.33 & 0.33 \\
Zero Inertia & 0.27 & 0.28 & 0.29 & 0.32 & 0.32 & 0.33 & 0.33 & 0.33 & 0.33 & 0.33 \\
Kinematic Wave & 0.27 & 0.28 & 0.29 & 0.32 & 0.59 & 7.59 & 15.93 & 33.04 & 50.57 & 68.99 \\
\hline
\end{tabular}

In Table 6 for different Manning's roughness coefficients amount of error in full hydrodynamic and zero inertia models is equal. In these two models for increase in Manning's roughness coefficient amount of error was increased until $n=0.15$. After this amount, error remained constant thus $n=0.15$ determined as critical discharge. In full hydrodynamic and zero inertia models whatever amount of Manning's roughness coefficient is less, accuracy of simulation models is more. In kinematic wave model the best simulation occurred in $n=0.15$ and for Manning's roughness coefficient more than this amount, error increased. To simulation of border and basin irrigations with Manning's roughness coefficient of more than 0.15 should be careful in using this model. Because while $n$ increase amount of infiltrated water decrease and more depth of water there is above of field thus changes of depth is not negligible. It is inconsistent with kinematic wave assumption (Equation (4)).

Table 7 shows changes of models error for different field slope. For increasing of filed slope until amount of 0.01 full hydrodynamic and zero inertia models had not any difference but for more increasing of $S_{0}$ due to the increasing of velocity, accuracy of zero inertia model dropped. Because neglected velocity terms in Equation of zero inertia model (Equation (3)). In kinematic wave model, while field slope was low (basin irrigation) error of model was high. Because according to the Equation (2), energy gradient assumed equal to field slope and while field slope was close to zero (basin irrigation), it was not a true assumption because energy gradient was more than zero. According to the Table 8 accuracy of simulation increase in all three models in light soil textures. In kinematic wave model due to effect of Kostiakov infiltration parameters error was high in clay and heavy clay soil textures. Because in this soils amount of infiltration was very low and volume of water above of field level caused assumptions of Equation (4) were not properly. Figure 1 shows the simulation was performed using SIRMOD software for full hydrodynamic and zero inertia models in clay soil texture.

Table 7. Changes of models error for different field slopes

\begin{tabular}{|c|c|c|c|c|c|c|c|c|c|c|}
\hline \multirow{2}{*}{ Model } & \multicolumn{10}{|c|}{$\mathrm{S}_{0}(\mathrm{~m} / \mathrm{m})$} \\
\hline & 0.00050 & 0.00080 & 0.00100 & 0.00150 & 0.00196 & 0.00500 & 0.01000 & 0.02000 & 0.03000 & 0.04000 \\
\hline Full Hydrodynamic & 0.28 & 0.30 & 0.30 & 0.31 & 0.32 & 0.33 & 0.34 & 0.36 & 0.39 & 0.40 \\
\hline Zero Inertia & 0.28 & 0.30 & 0.30 & 0.31 & 0.32 & 0.33 & 0.34 & 0.37 & 0.47 & 0.48 \\
\hline Kinematic Wave & 14.96 & 14.96 & 14.96 & 3.75 & 0.32 & 0.33 & 0.38 & 0.38 & 0.47 & 0.48 \\
\hline
\end{tabular}


Table 8. Changes of models error for different intake families

\begin{tabular}{|c|c|c|c|c|c|c|c|c|c|c|}
\hline \multirow{3}{*}{ Soil texture } & \multicolumn{10}{|c|}{ IF } \\
\hline & 0.02 & 0.05 & 0.15 & 0.20 & 0.35 & 0.45 & 0.70 & 0.80 & 1.00 & 4.00 \\
\hline & $\begin{array}{l}\text { Heavy } \\
\text { clay }\end{array}$ & Clay & $\begin{array}{l}\text { Light } \\
\text { clay }\end{array}$ & $\begin{array}{l}\text { Clay } \\
\text { loam }\end{array}$ & $\begin{array}{c}\text { Silt } \\
\mathrm{y}\end{array}$ & $\begin{array}{l}\text { Silty } \\
\text { loam }\end{array}$ & $\begin{array}{l}\text { Silty } \\
\text { loam }\end{array}$ & $\begin{array}{l}\text { Sandy } \\
\text { loam }\end{array}$ & $\begin{array}{l}\text { Sandy } \\
\text { loam }\end{array}$ & $\begin{array}{c}\text { Sand } \\
\mathrm{y}\end{array}$ \\
\hline \multicolumn{11}{|l|}{ Model } \\
\hline $\begin{array}{c}\text { Full } \\
\text { Hydrodynamic }\end{array}$ & 1.39 & 1.23 & 0.80 & 0.65 & 0.41 & 0.32 & 0.05 & 0.05 & 0.05 & 0.05 \\
\hline Zero Inertia & 1.39 & 1.23 & 0.80 & 0.65 & 0.41 & 0.32 & 0.05 & 0.05 & 0.05 & 0.05 \\
\hline Kinematic Wave & 141.16 & $\begin{array}{c}68.7 \\
8\end{array}$ & 1.04 & 0.65 & 0.41 & 0.32 & 0.31 & 0.21 & 0.20 & 0.05 \\
\hline
\end{tabular}

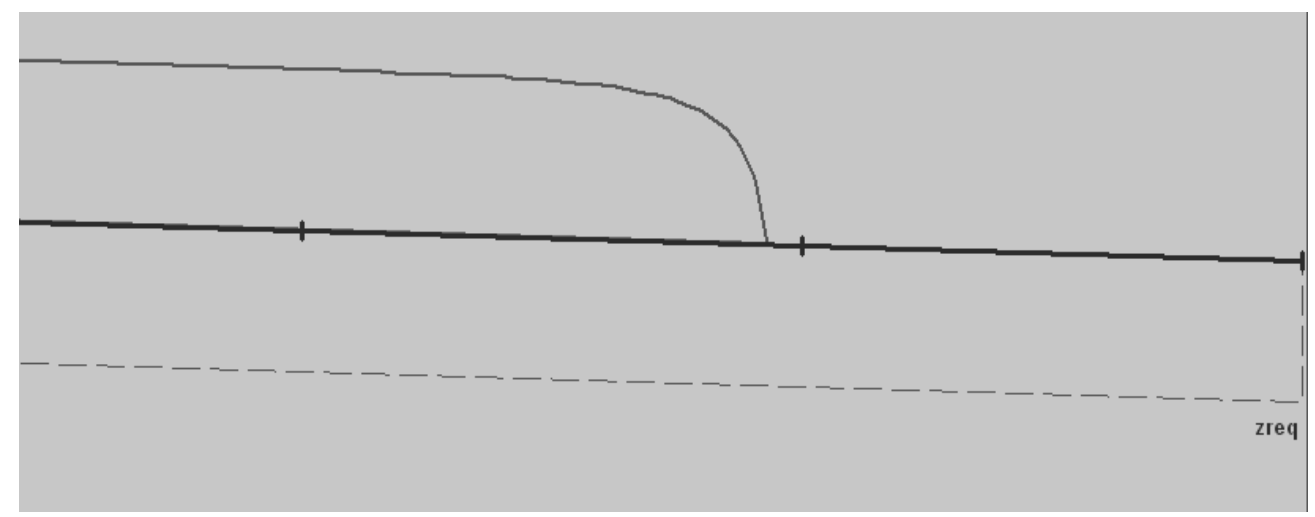

Figure 1. Simulation of full hydrodynamic and zero inertia models using SIRMOD software

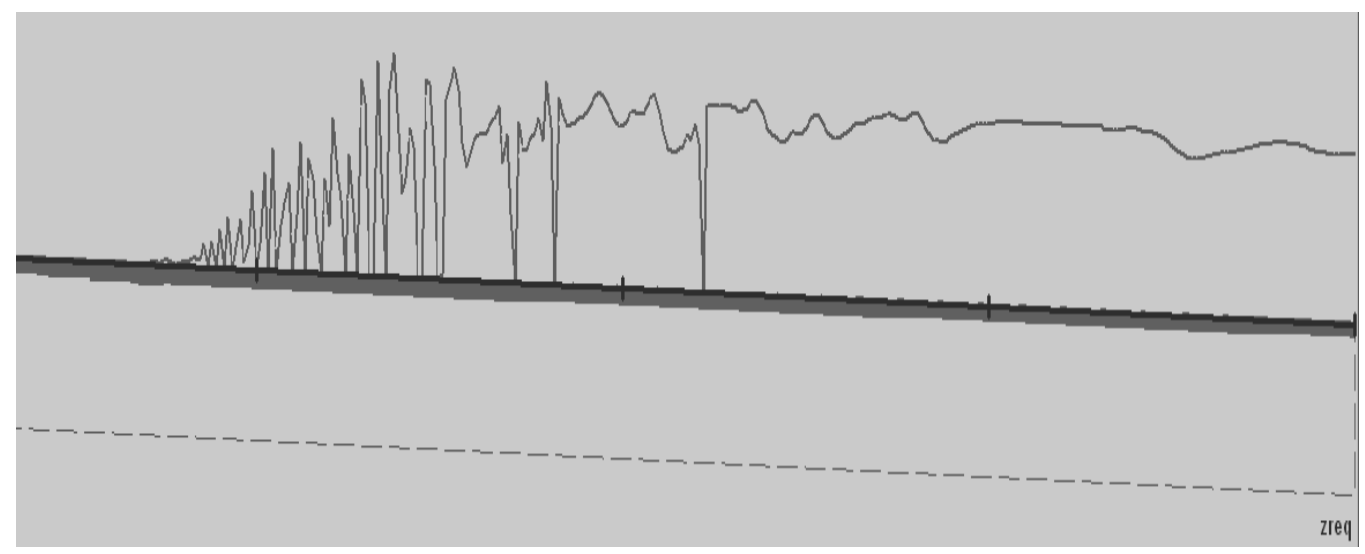

Figure 2. Simulation of kinematic wave model using SIRMOD software

In Figure 1, shape of waterfront is similar to the actuality thus error of full hydrodynamic and zero inertia models is low. Figure 2 shows the simulation was performed using SIRMOD software for kinematic wave model in clay soil texture.

As indicated in Figure 2, the water moves over the surface of field is such as a wave. So this model is called kinematic wave and error of this model is higher than other two models.

\section{Conclusions}

In this paper, using SIRMOD software ability of full hydrodynamic, zero inertia, and kinematic wave models were compared in border and basin irrigation. To summarize, it could be concluded that: 
Full hydrodynamic and zero inertia models were very powerful in simulation process.

In all three models for increase in cutoff time until 5-6 hr, amount of error increased and then remained constant.

In full hydrodynamic and zero inertia models for increase in Manning's roughness coefficient amount of error was increased until $n=0.15$. After this amount, error remained constant thus $n=0.15$ determined as critical discharge.

In kinematic wave model the best simulation occurred in $\mathrm{n}=0.15$ and for Manning's roughness coefficient more than this amount, error increased. To simulation of border and basin irrigations with Manning's roughness coefficient of more than 0.15 should be careful in using this model. Because while $n$ increase amount of infiltrated water decrease and more depth of water there is above of field thus changes of depth is not negligible.

For steep slope due to the increasing of velocity and neglecting velocity terms in Equation of zero inertia model, accuracy of zero inertia model dropped.

In kinematic wave model, while field slope was low (basin irrigation) error of model was high.

In kinematic wave model due to effect of Kostiakov infiltration parameters error was high in clay and heavy clay soil textures.

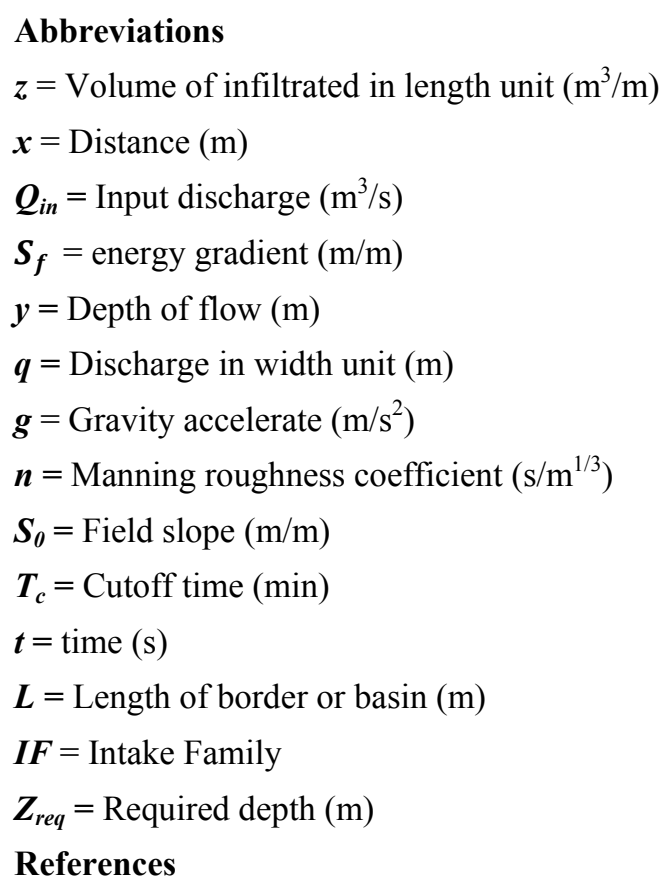

Alazba, A. A. (1998). Necessity for modification of management parameters when using low quality water, Agricultural Water Management, 36, 201-211. http://dx.doi.org/10.1016/S0378-3774(97)00053-X

Bautista, J. A. (1991). Validation of The Kinematic Simulation Of Surge Border Irrigation, Math. Comput. Modeling, 15(10), 39-48. http://10.1016/0895-7177(91)90089-P

Clemmens, A. J. (1981). Evaluation Of Infiltration Measurementes For Border Irrigation. Agricultural Water Management, 3, 251-267. http://dx.doi.org/10.1016/0378-3774(81)90010-X

Holzapfel, E. A., Jara, J., Zuñiga, C., Mariño, M. A., Paredes, J., \& Billib, M. (2004). Infiltration parameters for furrow irrigation. Agricultural Water Management, 68, 19-32. http://10.1016/j.agwat.2004.03.002

Hume, I. H. (1993). Determination of infiltration characteristics by volume balance for border check irrigation, Agricultural Water Management, 23, 23-39. http://dx.doi.org/10.1016/0378-3774(93)90018-6

Ito, H., Wallender, W. W., \& Raghuwanshi, N. S. (2005). Optimal Sample Size for Furrow Irrigation Design, Biosystems Engineering, 91(2), 229-237. http://dx.doi.org/10.1016/j.biosystemseng.2005.02.009

Khanna, M., \& Malano, H. M. (2007). Modeling of basin irrigation systems: A review. Agricultural Water Management, 83, 87-99. http://10.1016/j.agwat.2005.10.003

Maheshwari, B. L. (1992). Effects of recession criteria on prediction of recession times in border irrigation models, Agriculture water management, 21, 167-176. http://dx.doi.org/10.1016/0378-3774(92)90091-A 
Maheshwari, B. L., McMahon, T. A., \& Turner, A. K. (1990). Sensitivity analysis of parameters of border irrigation models. Agriculture water manement, 18, 277-287. http://dx.doi.org/10.1016/0378-3774(90)90011-M

Moravejalahkami, B., Mostafazadeh-Fard, B., Heidarpour, M., \& Abbasi, F. (2009). Research Paper: SW-Soil and Water Furrow infiltration and roughness prediction for different furrow inflow hydrographs using a zero-inertia model with a multilevel calibration approach. Biosystems Engineering, 103, 374-381. http://10.1016/j.biosystemseng.2009.04.005

Parsa, S. Z., \& Sepaskhah, A. R. (1991). Modification of the Fok-Bishop Solution for Determination of Water Advance in Border Irrigation. Journal of Agricultural Engineering Researches, 49, 127-132. http://dx.doi.org/10.1016/0021-8634(91)80033-B

Perez, C., Camacho, E., Roldan, J., Alcaide, M., \& Reca, J. (1995). A Control System of Furrow Irrigation in Real Time. Phys. Chem. Earth, 20(3-4), 351-358. http://dx.doi.org/10.1016/0079-1946(95)00048-8

Raghuwanshi, N. S., \& Wallender, W. W. (1998). Optimal Furrow Irrigation Scheduling Under Heterogeneous Conditions. Agricultural Systems, 58(1), 39-55. http://dx.doi.org/10.1016/S0308-521X(98)00030-4

Raghuwanshi, N. S., \& Wallender, W. W. (1998). Optimization of furrow irrigation schedules, designs and net return to water. Agricultural Water Management, 35, 209-226. http://dx.doi.org/10.1016/S0378-3774(97)00037-1

Ram, R. S., \& Singh, V. P. (1982). Evaluation of Models of Border Irrigation Recession. Journal of Agricultural Engineering Researches, 27, 235-252. http://dx.doi.org/10.1016/0021-8634(82)90065-8

Reddy, J. M., \& Clyma, W. (1982). Analysis Of Basin Irrigation Performance With Variable Inflow Rate. Agricultural Water Management, 5, 295-308. http://dx.doi.org/10.1016/0378-3774(82)90008-7

Walker, W. R., \& Humpherys, A. S. (1984). Kinematic-Wave Furrow Irrigation Model. Journal of Irrigation and Drainage Engineering, 109(4), 377-392. http://dx.doi.org/10.1061/(ASCE)0733-9437(1983)109:4(377)

Yityew, M. (1987). Interrelationship of Performance Parameters for Irrigation Borders. Agricultural Water Management, 12, 221-230. http://dx.doi.org/10.1016/0378-3774(87)90014-X 